\title{
Response to "A design framework for enhancing engagement in student-centered learning: own it, learn it, and share it": a design perspective
}

\author{
Xiaoqing $\mathrm{Gu}^{1}$ (iD \\ Accepted: 10 November 2020 / Published online: 8 January 2021 \\ (c) Association for Educational Communications and Technology 2021
}

\begin{abstract}
This essay is a response to the special issue call on the theme of Shifting to digital: Informing the rapid development, deployment, and future of teaching and learning. In this essay, the author first described the needs of student-centered learning that emerged from the current full-scale online teaching and learning practice due to the pandemic. With these needs, the author revisited the published article of A design framework for enhancing engagement in student-centered learning: own it, learn it, and share it (Lee and Hannafin, in Educ Technol Res Dev 64(4):707-734, 2016), discussed its value, application, and future development.
\end{abstract}

Keywords Response $\cdot$ Student-centered learning $\cdot$ Value $\cdot$ Application

What does real-life student-centered learning look like and what can we learn from it? Full-scale online learning during the COVID-19 pandemic provides us a novel understanding of how to support the self-directed learning of students when it became indispensable in such an extreme circumstance.

We conducted two rounds of research on the online learning and teaching of K12 schools before the spring semester approached its end. The first round was conducted in Shanghai to depict the new ways of schooling online. The second round was conducted countrywide to understand the experience of administrators, teachers, and learners of online teaching and learning during the pandemic. Plenty of lessons were learned for the future development of online learning. However, one particular point worth noting is how to support self-directed learning (SDL) when students have to study on their own devices and interact remotely with teachers.

Research indicates that online learning often situates the control of implementation with the learner (Song and Hill 2007). It became so crucial for online learning that learners take the initiative, with or without the help from others, in diagnosing their learning needs, formulating learning goals, identifying and addressing gaps in learning, identifying material

Xiaoqing $\mathrm{Gu}$

xqgu@ses.ecnu.edu.cn

1 Department of Educational Information Technology, East China Normal University, Shanghai, China 
resources, choosing and carrying out learning strategies, and evaluating learning outcomes (Knowles 1975; Loyens et al. 2008).

SDL encompasses a range of cognitive and meta-cognitive skills, all of which influence learning in various ways (Robertson 2011). During the pandemic, most students experienced full-scale online learning for the first time. Their SDL abilities play an important role in their online learning performance (Moore and Kearsley 2005). Students with a high level of SDL ability are likely to exhibit a high level of self-efficacy for learning and performance as well as a high level of effort regulation (Olga and Angela 2007). Moreover, they can show a high level of self-management and self-monitoring and a more positive learning motivation (Cameron 1997). They can also be more efficient in pinpointing their learning needs and learning resources; formulating learning goals, learning plans, and activities; and evaluating learning outcomes (Cheng et al. 2010).

Teachers play a key role in helping students transition smoothly from teacher-directed learning to SDL. This role requires teachers to develop new pedagogical approaches to increase students' metacognition (Reingold et al. 2008), thereby helping with self-awareness and self-regulation.

Bearing this requirement in mind, revisiting the article "A design framework for enhancing engagement in student-centered learning: own it, learn it, and share it" (Lee and Hannafin 2016) would provide new insight into the time of shifting to digital.

\section{Impact/value}

As for the guideline of teachers to design new pedagogical approaches to develop students' SDL, this article provides a valuable framework. The framework can be simplified with the phrase "own it, learn it, and share it," which is not only straightforward but also well established in theoretical analysis.

This design framework is theoretically sound with a thorough theoretical analysis encompassing the motivational, cognitive, social, and affective aspects of learning. For the motivational factor of learning, self-determination theory was analyzed to interpret the design guideline of own it. Epistemology angle and constructivism analysis can explain the design guideline of learn it, where learners construct meaning by assuming the agency of learning. By contrast, the analysis of constructionists makes sense of the design guideline of share it, in which the social and affective aspects of learning are involved for meaningful learning output.

The design framework this article proposed has value in the "Shift to Digital" (Hannafin and Hannafin 2009; Woloshyn et al. 2017) because it is well documented on theoretical analysis, covering all constructs of student-centered learning (Becker et al. 2015) and how these constructs contribute to learning.

\section{Application}

Importantly, practical design guidelines aligned with three key phrases are provided, which could be of value for teachers down the road to design online learning to develop student's self-regulation.

For example, along with own it, one of the guidelines is "provide opportunities to set specific personal goals" (Lee and Hannafin 2016, p.723). In addition to the theoretical 
analysis on this guideline, practical suggestions such as providing opportunities for students to "document their personal goals," "make a plan of action," or "reflect on their achievement or failure" are described as the main content of the article. These detailed practical notes would inform teachers on how to take action to "Shift to Digital" by designing the self-regulation learning of students.

\section{Limitations and constraints}

Concrete examples could further demonstrate what a particular practical note means to a designer (Reingold et al. 2008), for example, what it looks like to "provide opportunities for students to document their personal goals." The lack of real cases to further illustrate the guidelines is one of the limitations of the article.

The second one is that not all 10 guidelines are evenly detailed in the description of practical actions. For example, a designer would be disappointed if $s / h e$ expects to find information on what to do to promote dialogue among students.

Last but not least, as the authors already pointed out, validated instruments would be important components to the design framework to assess the effectiveness of the guideline in supporting student learning processes and outcomes.

\section{Future suggestions}

While I can see the potentials in these guidelines, I would like to see experiments of the designs with the guidelines and the instruments. If these experiments are carried out, I would like to see real cases that could be amended along with each and every guideline. Accordingly, this design framework could be of practical value for designers to develop students' self-regulated learning.

\section{Compliance with ethical standards}

Conflict of interest There is no potential conflict of interest in this essay.

\section{References}

Becker, M. R., Winn, P., \& Erwin, S. L. (2015). Student-centered, e-Learning design in a university classroom. In J. Pedro Isaías, S. Michael, I. Dirk, \& G. S. Demetrios (Eds.), E-learning systems, environments and approaches (pp. 229-246). New York: Springer. https://doi.org/10.1007/978-3-319-05825 $-2 \_16$.

Cameron, D. R. (1997). Self-directed learning: Toward a comprehensive model. Adult Education Quarterly, $48(1), 18-33$.

Cheng, S. F., Kuo, C. L., Lin, K. C., \& Lee-Hsieh, J. (2010). Development and preliminary testing of a selfrating instrument to measure self-directed learning ability of nursing students. International Journal of Nursing Studies, 47(9), 1152-1158.

Hannafin, M. J., \& Hannafin, K. M., et al. (2009). Cognition and student-centered, web-based learning: issues and implications for research and theory. In J. Michael Spector (Ed.), Learning and instruction in the digital age (pp. 11-23). New York: Springer. https://doi.org/10.1007/978-1-4419-1551-1_2.

Knowles, M. S. (1975). Self-directed learning: A guide for learners and teachers. New York: Association Press. 
Lee, E., \& Hannafin, M. J. (2016). A design framework for enhancing engagement in student-centered learning: Own it, learn it, and share it. Educational Technology Research and Development, 64(4), 707-734. https://doi.org/10.1007/s11423-015-9422-5.

Loyens, S. M. M., Magda, J., \& Rikers, R. M. J. P. (2008). Self-directed learning in problem-based learning and its relationships with self-regulated learning. Educational Psychology Review, 20(4), 411-427.

Moore, M., \& Kearsley, G. (2005). Distance education: A systems view (2nd ed.). Belmont, CA: Thomson Wadsworth.

Olga, N. S., \& Angela, D. B. (2007). The relationship between adult students' instructional technology competency and self-directed learning ability in an online course. Human Resource Development International, 10(4), 417-435.

Reingold, R., Rimor, R., \& Kalay, A. (2008). Instructor's scaffolding in support of student's metacognition through a teacher education online course: A case study. Journal of Interactive Online Learning, 7(2), $139-151$.

Robertson, J. (2011). The educational affordances of blogs for self-directed learning. Computers \& Education, 57(2), 1628-1644.

Song, L., \& Hill, J. R. (2007). A conceptual model for understanding self-directed learning in online environments. Journal of Interactive Online Learning, 6(1), 27-42.

Woloshyn, V. E., Bajovic, M., \& Worden, M. M. (2017). Promoting student-centered learning using iPads in a grade 1 classroom: Using the digital didactic framework to deconstruct instruction. Computers in the Schools, 34(3), 152-167.

Publisher's Note Springer Nature remains neutral with regard to jurisdictional claims in published maps and institutional affiliations.

Xiaoqing Gu is Professor of Educational Technology in the Faculty of Education, East China Normal University, China. Her main research interests are learning science, learning design and CSCL 